\title{
Privileged Allies in Lesbian and Gay Rights Activism: Gender, Generation, and Resistance to Heteronormativity
}

\author{
Samantha A. Montgomery* and Abigail J. Stewart \\ University of Michigan
}

In two studies, we examined the relationship between resistance to heteronormativity and political engagement among heterosexuals. In the first, we examined the relationship between awareness of heterosexual privilege, resistance to heteronormativity, and engagement in lesbian and gay rights activism among contemporary heterosexual college students. As expected, women scored higher than men on both heterosexual privilege awareness and resistance to heteronormativity. For women, both heterosexual privilege awareness and resistance to heteronormativity were related to engagement in lesbian and gay rights activism. In the second study, we examined heteronormative attitudes in three cohorts of women spanning 40 years (college graduates in 1951/2, 1972, and 1992), looking at both generational differences in endorsement of heteronormative attitudes and the relationship of these attitudes to engagement in lesbian and gay rights activism. As expected, the two younger cohorts of women were significantly less heteronormative than the oldest cohort. Implications of these results are discussed.

Privilege, defined as socially conferred benefits or advantages that result from mere membership in a particular social group, is now well understood to confer both blindness to others' experience, and to one's own power (Pratto \& Stewart, 2012). Although systems of privilege exist worldwide, this article focuses on a particular context- the United States. In two studies, we examine some conditions

\footnotetext{
* Correspondence concerning this article should be addressed to Samantha A. Montgomery, Departments of Psychology and Women's Studies, University of Michigan, 3256 East Hall, Ann Arbor, MI 48109 [e-mail: smontgo@umich.edu].

We are grateful to Nicola Curtin, L. E. Hunter, Nicky Newton, and Danielle Shapiro for feedback on an earlier draft of this article. We also thank the faculty and graduate student members of three research groups at the University of Michigan that have provided insight and suggestions on the projects as they were developed: Sexual Diversity, Gender and Respect in Organizations, and Gender and Personality in Context.
} 
under which people with heterosexual privilege become allies in the struggle against it. Russell (2011) examined the different motives of heterosexual allies; we expand this discussion to explore the role of gender, generation, and resistance. We are fortunate to be able to draw on a rich literature on the operation of privilege, as well as on the nature of intersectionality (Cole, 2008; Hurtado, 1996; Stewart $\&$ McDermott, 2004).

Individuals who hold privilege are usually not only unaware of their privilege, but often feel powerless (Stewart, Latu, Branscombe, Phillips, \& Denney, 2012) to do anything about it. Sociologist Erving Goffman provided insight into why this is so:

In an important sense there is only one complete unblushing male in America: a young, married, White, urban, northern, heterosexual Protestant, father, of college education, fully employed, of good complexion, weight, and height, and a recent record in sports. ... Any male who fails to qualify in any one of these ways is likely to view himself-during moments at least — as unworthy, incomplete, and inferior. (Goffman, 1963, p. 128)

This account highlights not only the range of statuses that confer privilege in the United States, but also the many ways in which privilege is compromised (see also Hill Collins, 2003). Part of the reason it is so difficult for individuals to recognize their privilege is that they are simultaneously privileged and subordinated by different social statuses, and the subordinate statuses have psychological weight even when they are not particularly important socially. At the same time it is clear that some individuals do recognize their privilege and take action to use it to equalize status differentials from which they currently benefit (Berube, 2003; McIntosh, 1988; Messner, 2003). As Elizabeth Cole has argued in a series of important papers about intersectionality (Cole, 2008, 2009; Cole \& Luna, 2010), individuals who hold intersecting social identities that are differentially privileged (White and female, gay and male) may be particularly likely to be able to draw on a subordinate social identity to recognize the privilege they hold in a dominant one. Of course this does not preclude the possibility of recognizing privilege from an entirely privileged position; it simply suggests that intersections of dominance and subordination will be particularly effective locations from which to recognize one's own privilege and develop the "moral outrage" about it that has been understood to fuel efforts to change current inequalities (Burns, 2004; Case, 2012; Iyer, Leach, \& Pedersen, 2004).

One of the recognized practices that operates not only to normalize privilege, but to obscure the system of inequality that maintains it, is the creation of social norms that appear neutrally to uphold it (Pratto \& Stewart, 2012). Claims of biological essentialism or other forms of determinism have been recognized as justifying the status quo (Cole, Avery, Dodson, \& Goodman, 2012). Definitions of "merit" that appear "neutral" have been demonstrated to justify privileges held on the basis of gender, race and ethnicity, and social class (Burns, 2004). Equally, heteronormativity has been defined as "the view that institutionalized 
heterosexuality constitutes the standard for legitimate and expected social and sexual relations" (Ingraham, 1999, p. 17). Whereas homophobia and homonegativity consist of prejudiced attitudes toward sexual minorities (Herek, 1988), heteronormativity is an internalized set of expectations about gender and sexuality. Indeed, heteronormative assumptions are those that view heterosexuality as natural, inevitable, and desirable (Kitzinger, 2005). As a special case of social norms, heteronormativity includes some aspects of prescriptive gender roles (Eagly, 1987), normative expectations about heterosexuality (Hegarty, Pratto, \& Lemieux, 2004), and justifications for heterosexual privilege (Massey, 2009). Psychologically, heteronormativity is comprised of a constellation of attitudes, affective responses, and beliefs that on the one hand value and support heterosexual privilege, and on the other hand stigmatize sexual minorities as well as heterosexuals who violate social norms (Hegarty, Pratto, \& Lemieux, 2004; Herek, 1988).

Although recent research has explored the psychological implications of heteronormativity and related outcomes among sexual minorities (Dalley \& Campbell, 2006; Hequembourg, \& Brallier, 2009; Mann, 2007; Rosenfeld, 2009), there is also growing interest in how heteronormativity affects heterosexuals (e.g., Ingraham, 1996; Wilkinson \& Kitzinger, 1993) and women as opposed to men (Nielson, Walden, \& Kunkel, 2000). Across all groups, different psychological reactions to societal prescriptions of heteronormativity (e.g., internalizing heteronormative attitudes and beliefs, ambivalence, or rejecting heteronormativity altogether) are important. For example, Massey's (2009) resist heteronormativity scale assesses variations in feeling restricted by prescriptive gender roles and rejecting certain assumptions about sexuality. However, the relationship between resistance to heteronormativity and political engagement has not been examined.

Furthermore, the relationship between heteronormativity and political engagement may differ by generation. Attitudes toward gay rights and same-sex marriage have become more positive in the past few decades (Brewer, 2003; Brewer \& Wilcox, 2005; Egan \& Sherrill, 2005). Moreover, age is correlated with negative attitudes toward lesbians and gay men, suggesting that the shift across time may be partly a cohort effect (Egan, Persily, \& Wallsten, 2008). Similarly, support for women's rights has generally increased over time (Huddy, Neely, \& Lafay, 2000), and Zucker (1998) reports cohort differences in feminist attitudes and identities.

Although these studies suggest that there have been generational changes in attitudes about gender and sexual minorities, little is known about changes in overall heteronormativity during this period. For this article we were able to examine cohort differences in the degree to which a contemporary generation of college students and three generations of college alumnae held heteronormative beliefs. In two studies with different samples, we examined the relationship between resistance to heteronormativity and political engagement. We viewed the 
intersection of heterosexuality and gender as a particularly important backdrop for both studies. In the first, we directly examined the hypothesis that straight women would be more likely to recognize their heterosexual privilege than straight men. We also examined the relationship between awareness of heterosexual privilege, resistance to heteronormativity, and engagement in lesbian and gay rights activism among both groups of contemporary heterosexual college students. Specifically, our hypotheses were as follows:

(1) Based on the notion that simultaneously holding subordinate and privileged identities should increase insight into privilege, heterosexual women will report higher levels of heterosexual privilege awareness and of resistance to heteronormativity than heterosexual men in Study 1.

(2) Resistance to heteronormativity and heterosexual privilege awareness will be positively related to engagement in lesbian and gay rights activism in Study 1 , especially among women.

In the second study, we examined heteronormative attitudes in three cohorts of women (women who graduated from college in 1951/2, 1972, and 1992), looking at both generational differences in endorsement of heteronormative attitudes and the relationship of these attitudes to engagement in lesbian and gay rights activism. Using this sample of alumnae, we examined generational differences in the internalization of heteronorms and how heteronormativity was related to political engagement. Specifically, our hypotheses were that:

(1) Younger cohorts of heterosexual women will score lower on heteronormativity than older cohorts in Study 2.

(2) Among heterosexual women alumnae, lower levels of heteronormativity will be associated with more political engagement in lesbian and gay rights activism.

\section{Study 1: Method}

This study examined awareness of heterosexual privilege, resistance to heteronormativity, and engagement in lesbian and gay rights activism among a sample of 193 college students from a large, public, research university in the Midwest. We recruited participants from three different undergraduate classes; participants were informed that they would be taking a survey about their experiences in college and were asked to complete a paper and pencil survey during class. 


\section{Participants}

Participants in this study included the 166 self-identified heterosexual college students in the sample. On average, the participants were 20.15 years old, and $74.1 \%(n=123)$ self-identified as female. The sample was predominantly White in terms of racial-ethnic background: $68.1 \%$ self-identified as White European, $14.5 \%$ self-identified as Asian, 6\% self-identified as Black African, 6\% selfidentified as Latina, 2.4\% self-identified as Middle Eastern, 1.8\% self-identified as Native American, and $0.6 \%$ self-identified as other.

\section{Measures}

Awareness of heterosexual privilege. Heterosexual privilege awareness was assessed in terms of five items originally written by straight-identified students from Earlham College who had read McIntosh's (1988) essay on white privilege. This list of the daily effects of straight privilege was retrieved from the Internet and discussed with faculty and graduate student members of three research groups at the University of Michigan. From the list, five items were selected for this study; consent to use was granted by the individual who posted them on the Internet (Hunter, 2010). Participants were asked to indicate how strongly they agreed with items on a scale from 1 (strongly disagree) to 5 (strongly agree). The items were: I do not fear revealing my sexual orientation to friends or family members; I can be open about my sexual orientation without having to worry about my job; People don't ask me why I chose my sexual orientation; I can choose to not think politically about my sexual orientation; I can walk in public with a significant other and people won't stare. A summed score was calculated for each participant. Cronbach's alpha was 0.78 for the sample. Scores on this measure ranged from 9 to 25 , with higher scores indicating higher levels of heterosexual privilege awareness. Because the overall mean for the sample was quite high, we created a 3 -point ordinal scale that recoded scores from 0 to 20 into 1, scores from 21 to 24 into 2 , and high scores of 25 into $3(x=2.40, S D=0.79)$.

Resistance to heteronormativity. Psychological resistance to heteronormativity was assessed using a scale created by Massey (2009) for use with samples heterogeneous with respect to sexuality. Participants were asked to indicate how strongly they agreed with eight statements on a scale from 1 (strongly disagree) to 5 (strongly agree). Sample items include: "I feel restricted by the sexual rules and norms of society," "I worry about the privileges I get from society because of my sexual orientation," and "I believe that most people are basically bisexual." A summed score was calculated for each participant. Scores on this measure ranged from 8 to 36 , with higher scores indicating higher levels of resistance to 
heteronormativity. The overall mean score for the sample was $17.20(S D=6.58)$. Cronbach's alpha was 0.86 for the sample.

Lesbian and gay rights activism. Lesbian/gay rights activism was assessed using an item from previous research on activism (Duncan, 1999). Participants were asked to indicate the types of activity in which they were involved for a variety of causes cause: signing a petition, contributing money, attending a meeting, writing a letter to and/or calling a public official, being an active member in an organization, and/or attending a rally or demonstration. For each of these six kinds of engagement, participants could receive a score of 0 (was not active) or 1 (was active). A summed score of 0-6 was calculated for each participant. Mean score for the sample was $0.38(S D=0.70)$.

\section{Study 1: Results}

\section{Gender Differences}

As expected, women scored higher than men on both heterosexual privilege awareness and resistance to heteronormativity. For heterosexual privilege, the mean for women was 23.56 (2.4) and 22.34 (3.3) for men, $t(158)=2.17, p<.05$. For resistance to heteronormativity, the mean for women was 17.92 (6.71), for men $15.10(5.73), t(159)=-2.40, p<.05$. Men and women did not differ significantly on lesbian/gay rights activism (means of 0.47 [SD $=-.19$ ] for women and 0.39 $[S D=-.31]$ for men, $t=-1.74$, n.s.).

\section{Correlates of Lesbian/Gay Rights Activism}

In this sample of heterosexual students, awareness of heterosexual privilege and resistance to heteronormativity were uncorrelated with each other $(r=-.10$, n.s.). Heterosexual privilege awareness was also uncorrelated with lesbian/gay rights activism ( $r=.12$, n.s.), but resistance to heteronormativity was significantly positively correlated with lesbian/gay rights activism, as predicted $(r=.36$, $p<.001)$.

\section{Predictors of Lesbian/Gay Rights Activism}

A multiple regression tested whether gender, heterosexual privilege awareness, and resistance to heteronormativity predicted lesbian and gay rights activism (Table 1). Results confirmed there were significant main effects for heterosexual privilege awareness and resistance to heteronormativity; both were independently associated with lesbian/gay rights activism for heterosexual students, when controlling for each other. There was no main effect of gender on lesbian and gay 
Table 1. Multiple Regression Predicting Lesbian and Gay Rights Activism Among Heterosexual Students

\begin{tabular}{lrcc}
\hline & $b$ & $S E b$ & $\beta$ \\
\hline Step 1 & & & \\
$\quad$ Constant & -82 & 0.28 & \\
Gender & .09 & 0.13 & 0.70 \\
Heterosexual privilege & 0.18 & .07 & $2.61^{*}$ \\
Resistance to heteronormativity & .04 & .01 & $4.37^{* * *}$ \\
Step 2 & & & \\
Constant & 1.44 & 1.10 & $-1.10^{*}$ \\
Gender & -1.79 & 0.90 & -.06 \\
Heterosexual privilege & -.01 & 0.11 & $4.31^{* * *}$ \\
Resistance to heteronormativity & .04 & .01 & $2.14^{*}$ \\
Gender*heterosexual privilege & .08 & .04 & \\
\hline Note: $R^{2}=.14$ for Step 1: $\Delta R^{2}=.04$ for Step 2 $(p s<.001){ }^{*} p<.05,{ }^{* *} p<.01,{ }^{* * *} p<.001$.
\end{tabular}

Note: $R^{2}=.14$ for Step 1: $\Delta R^{2}=.04$ for Step $2(p s<.001){ }^{*} p<.05,{ }^{* *} p<.01,{ }^{* * *} p<.001$.

rights activism. However, there was an interaction between heterosexual privilege and gender, which indicated that heterosexual privilege awareness predicted lesbian and gay rights activism for women, but not for men. Moreover, women who scored higher in heterosexual privilege awareness engaged in more ally activism than women who scored lower in heterosexual privilege awareness. Because our dependent variable was skewed, we also dichotomized the activism scale into a binary variable and tested predictors via a logistic regression. The logistic regression revealed similar results to our multiple regression, so we decided to preserve the variance in activism scores (which are always skewed, because most people are not "activist") and keep it a continuously coded variable.

\section{Study 1: Discussion}

Heterosexual women students in this study were, as expected, more likely to report awareness of heterosexual privilege, and to express resistance to heteronormativity. Moreover, expressing both of these views was significantly related to lesbian/gay activism for them. In contrast, heterosexual male students were not only less likely to express these views, but only resistance to heteronormativity was significantly positively related to lesbian/gay activism.

These findings underscore the way in which heterosexual men and women react to heteronormativity differently. These findings suggest that heterosexual women are, as we predicted, particularly able to draw on their joint position as members of both a dominant group (heterosexuals) and a subordinate group (women) to recognize their privilege, to feel resistant toward heteronorms, and to 
use those experiences to motivate their ally activism on behalf of gays and lesbians. Heterosexual men, perhaps because they lack a subordinate status (though of course they may have one we did not assess) or merely because of their double privilege as straight men in this culture, may view their privilege simply as a fact, rather than an unearned advantage.

These analyses focused on predictors of ally activism within a single age group. We next examined these same predictors of lesbian and gay rights activism across three generations of heterosexual women. Specifically, we were interested in the relationship between generation, heteronormativity, and activism.

\section{Study 2: Method}

This study is a secondary analysis of data from three cohorts of alumnae from the University of Michigan collected in 1996 (Zucker, 1998). The original sample included 333 women from the University of Michigan classes of 1951 or 1952, 1972, and 1992 who were asked to complete a pencil and paper questionnaire via regular mail.

\section{Participants}

Data analyzed in this study were drawn from the 305 participants who selfidentified as heterosexual. At the time of data collection, women in the cohorts were in their 60s, 40s, and 20s, respectively. The sample was predominantly White in terms of racial-ethnic background: $93.3 \%$ identified as White European, 3.7\% identified as Asian, 1.0\% identified as Black African, $0.7 \%$ identified as Latina, $0.3 \%$ identified as Native American, and $1.0 \%$ identified as multiracial. All of the women were highly educated: $4.6 \%$ of the sample were students at the time of data collection, $38.9 \%$ held BA degrees, and the rest held a graduate degree of some kind. The sample tended to feel economically secure: $46.9 \%$ of the oldest cohort, $51.9 \%$ of the middle cohort, and $51.3 \%$ of the youngest cohort rated their economic resources to be "had more than enough to get by."

\section{Measures}

Heteronormativity proxy. Heteronormativity is conceptually unrelated to sexual attraction, interest, or activity. For example, women who engage in sex exclusively with men or with women, and women who engage in sex with both all may vary in the degree to which they hold heteronormative values and attitudes. Therefore none of the heteronormativity items in this study assess sexual identity, interest, or behavior directly. Instead, they focus on past and present internalization of heteronorms. 
Six items from secondary data were used to construct a proxy indicator of heteronormativity: discontent with the amount of power lesbians have, positive feelings toward lesbians (reverse-scored), and four items assessing the respondents' own expectations about marriage and children during adolescence and college. Although there are other components of heteronormativity (e.g., negative feelings about gay men, a belief that heterosexuality is "natural," etc.), we were constrained by the items available in the data set.

Power discontent assesses respondents' view of various groups' influence in society (Gurin, Miller, \& Gurin, 1980). Respondents were asked to judge the relative power held by lesbians (reverse-scored) on a scale ranging from 1 (too little) to 5 (too much). Thus, high ratings indicated more heteronormativity. Second, we included an item about lesbians from a measure that asked respondents to indicate how warmly they felt toward certain social groups via a feeling thermometer (Miller, 1982) with scores ranging from 0 to 100 degrees. Lower ratings indicated higher levels of heteronormativity. Finally, expectations about marriage and children during adolescence and college were measured via four items assessing whether or not participants recalled feeling that eventually they wanted to get married or become mothers when they were teenagers, and when they were in college. For each item the desire to be married or to have children was considered to be more heteronormative.

Each of the six items was standardized and a mean score was calculated, based on the standardized values, for each participant. Scores on this measure ranged from-9.88 to 7.16, with higher scores indicating higher levels of heteronormativity. Descriptive statistics for all of our measures are provided in Table 2. The overall mean score for the sample was $0.14(S D=3.88)$. Cronbach's alpha was 0.73 for the sample.

Activist engagement. Engagement with lesbian/gay rights was assessed using the same measure as Study 1.

Personal meaning of events. All of the women were asked how personally meaningful a list of 21 historical and social events were to them on a scale of 1 (not at all personally meaningful) to 3 (very personally meaningful). Six items from this larger scale were used to assess the convergent (three items) and divergent (three items) validity of the heteronormativity measure. First, the heteronormativity measure was expected to correlate positively with average ratings of three items: the lesbian/gay rights movement $(M=1.67, S D=0.66)$; the AIDS crisis $(M=2.11, S D=0.73)$; and the women's rights movement $(M=2.55, S D=$ 0.63). Cronbach's alpha for heteronormatively relevant events was 0.65 . Divergent validity was assessed by correlating the heteronormativity measure with the average rating of three conceptually unrelated items: 1980s bull market $(M=$ $1.60, S D=0.64)$; the Persian Gulf War $(1990-1991 ; M=1.83, S D=0.69)$; 
Table 2. Descriptive Characteristics of Measures

\begin{tabular}{|c|c|c|c|c|}
\hline & $1951 / 2$ & 1971 & 1992 & Overall \\
\hline Heteronormativity & $\begin{array}{c}\mathrm{M}=2.25 \\
\mathrm{SD}=3.38 \\
(\mathrm{n}=80)\end{array}$ & $\begin{aligned} M & =-.60 \\
\mathrm{SD} & =3.68 \\
(\mathrm{n} & =112)\end{aligned}$ & $\begin{aligned} \mathrm{M} & =-1.05 \\
\mathrm{SD} & =3.82 \\
(\mathrm{n} & =72)\end{aligned}$ & $\begin{aligned} \mathrm{M} & =0.14 \\
\mathrm{SD} & =3.88 \\
(\mathrm{n} & =264)\end{aligned}$ \\
\hline \multicolumn{5}{|l|}{ Personal meaning of events } \\
\hline Heteronormatively relevant events & $\begin{array}{r}\mathrm{M}=5.65 \\
\mathrm{SD}=1.54 \\
(\mathrm{n}=104)\end{array}$ & $\begin{aligned} \mathrm{M} & =6.49 \\
\mathrm{SD} & =1.52 \\
(\mathrm{n} & =146)\end{aligned}$ & $\begin{array}{c}\mathrm{M}=7.30 \\
\mathrm{SD}=1.22 \\
(\mathrm{n}=92)\end{array}$ & $\begin{aligned} \mathrm{M} & =6.45 \\
\mathrm{SD} & =1.58 \\
(\mathrm{n} & =342)\end{aligned}$ \\
\hline Heteronormatively irrelevant events & $\begin{aligned} \mathrm{M} & =5.45 \\
\mathrm{SD} & =1.41 \\
(\mathrm{n} & =103)\end{aligned}$ & $\begin{aligned} \mathrm{M} & =5.37 \\
\mathrm{SD} & =1.37 \\
(\mathrm{n} & =145)\end{aligned}$ & $\begin{array}{c}M=5.55 \\
\mathrm{SD}=1.48 \\
(\mathrm{n}=93)\end{array}$ & $\begin{aligned} \mathrm{M} & =5.45 \\
\mathrm{SD} & =1.41 \\
(\mathrm{n} & =341)\end{aligned}$ \\
\hline \multicolumn{5}{|l|}{ Activist engagement } \\
\hline Lesbian and gay rights & $\begin{array}{c}\mathrm{M}=0.34 \\
\mathrm{SD}=0.74 \\
(\mathrm{n}=89)\end{array}$ & $\begin{array}{r}\mathrm{M}=0.43 \\
\mathrm{SD}=0.83 \\
(\mathrm{n}=129)\end{array}$ & $\begin{array}{c}\mathrm{M}=0.69 \\
\mathrm{SD}=1.03 \\
(\mathrm{n}=72)\end{array}$ & $\begin{aligned} \mathrm{M} & =0.47 \\
\mathrm{SD} & =0.87 \\
(\mathrm{n} & =290)\end{aligned}$ \\
\hline Environmental & $\begin{array}{c}\mathrm{M}=1.89 \\
\mathrm{SD}=1.69 \\
(\mathrm{n}=96)\end{array}$ & $\begin{array}{r}\mathrm{M}=2.30 \\
\mathrm{SD}=1.62 \\
(\mathrm{n}=133)\end{array}$ & $\begin{array}{c}\mathrm{M}=1.70 \\
\mathrm{SD}=1.61 \\
(\mathrm{n}=76)\end{array}$ & $\begin{aligned} \mathrm{M} & =2.02 \\
\mathrm{SD} & =1.65 \\
(\mathrm{n} & =305)\end{aligned}$ \\
\hline
\end{tabular}

Note: Heteronormatively relevant events were the Lesbian and Gay Rights movement, the Women's Rights movement, and the AIDS crisis. Heteronormatively irrelevant events included the 1980s Bull Market, the end of the Cold War, and the Persian Gulf War.

and the end of the Cold War $(M=1.87, S D=0.70)$. Cronbach's alpha for heteronormatively irrelevant events was 0.40 , which is not surprising because these events were selected as unrelated.

\section{Study 2: Results}

\section{Validity of our Heteronormativity Indicator}

Women who scored higher on our indicator of heteronormativity were, as expected, significantly less likely than women who scored lower on heteronormativity to indicate that the lesbian/gay rights movement, the AIDS crisis, and the women's rights movement were personally meaningful to them (Table 3). Both women who were high and women who were low on heteronormativity, as expected, rated equally the personal meaningfulness of the 1980s bull market, the Persian Gulf War, and the end of the Cold War. 
Table 3. Correlations Between Heteronormativity and the Personal Meaning of Events by Cohort

\begin{tabular}{llccc}
\hline & \multicolumn{4}{c}{ Heteronormativity } \\
\cline { 2 - 5 } & $\begin{array}{c}1951 / 2 \\
(n=84)\end{array}$ & $\begin{array}{c}1972 \\
(n=116)\end{array}$ & $\begin{array}{c}1992 \\
(n=72)\end{array}$ & $\begin{array}{c}\text { Overall } \\
(n=274)\end{array}$ \\
\hline Heteronormatively relevant events & $-.30^{* *}$ & $-.26^{* *}$ & $-.27^{*}$ & $-.37^{* *}$ \\
Heteronormatively irrelevant events & -.04 & -.10 & -.01 & -.06 \\
\hline
\end{tabular}

Note: Heteronormatively-relevant events were the Lesbian and Gay Rights movement, the Women's Rights movement, and the AIDS crisis. Heteronormatively-irrelevant events included the 1980s Bull Market, the end of the Cold War, and the Persian Gulf War. $* p<.05, * * p<.01$.

\section{Heteronormativity and Generation}

To test our second hypothesis that the younger cohorts of women would be significantly less heteronormative than the older cohorts, we ran an analysis of variance. The average standardized score on heteronormativity was $2.25(S D=$ 3.38) for the oldest cohort, $-.60(S D=3.68)$ for the middle cohort, and -1.05 $(S D=3.83)$ for the youngest cohort. The ANOVA results showed that there were significant differences in heteronormativity among the cohorts, $F(2,261)=19.65$, $p<.001$. Post hoc analyses using the Scheffé post hoc criterion for significance indicated that women in the oldest cohort (1952) were significantly more heteronormative $(M=2.25, S D=3.38)$ than either the middle (1972; $M=-.60$, $S D=3.68)$ or youngest cohort $(1992 ; M=-1.04, S D=3.83)$. The younger two cohorts were not significantly different from each other.

\section{Heteronormativity and Activism}

As expected, women who scored lower on heteronormativity were more likely to participate in lesbian/gay rights activism $(r=-.28, p<.01)$. To rule out the possibility that heteronormativity is associated with all forms of activism, we examined its relationship to environmental activism; as predicted, heteronormativity was unrelated to that form of activism $(r=-.08$, n.s.).

We did not hypothesize that heteronormativity would motivate lesbian/gay rights activism separately in all three samples, because limited variance within generations (given our prediction of generational differences) would likely constrain the relationship. Nevertheless, we did examine the relationships, and found that heteronormativity was significantly related to lesbian/gay rights activism among women in the two younger cohorts $(r=-.30, p<.001$ for the youngest, and $r=-.29, p<.001$ for the middle); it was unrelated for the oldest cohort ( $r$ $=-.08$, n.s.). Heteronormativity was unrelated to environmental activism for all the three cohorts ( $r=-.04$ for the oldest, $r=-.06$ for the middle, and $r=-.08$ for the youngest). 


\section{Study 2: Discussion}

Although we were limited to items that already existed in this data set, we were able to construct a proxy indicator of heteronormativity. Like other psychological measures of heteronormativity (Habarth, 2008; Massey, 2009), items tapped into the components of social and sexual relations that both normalize heterosexuality (e.g., wanting to get married, wanting to have children, etc.) and marginalize sexual minorities (e.g., discontent with the degree of power held by lesbians, lack of positive feelings toward lesbians). During the time of data collection, as well as the period during which these women were socialized, getting married, and having children were nearly exclusively heterosexual life paths. Given expanded legal rights and technologies for sexual minorities, it is unclear if these practices are equally heteronormative for young children being raised now.

In our sample, this indicator of heteronormativity was related to conceptually relevant correlates (attaching meaning to some events and social movements) and unrelated to conceptually irrelevant correlates. It was also related to political engagement on behalf of lesbian and gay rights across generations of women.

Finally, generational differences were apparent. Women who reached young adulthood after Stonewall and the height of the women's movement were significantly less heteronormative according to our measure than the older women. Stewart and Healy (1989) argued that adolescents exposed to values radically different from the social norms of their childhood are likely to have these new ideas shape their personal identities. For the women of the middle cohort, coming of age during the peak of the sexual revolution may have been truly transformational. Stewart and Healy (1989) also proposed that growing up in environments already affected by dramatic social changes can influence core values and beliefs. Growing up in the period after movements had challenged norms about gender and sexuality may have shaped the assumptive frameworks and fundamental values of the youngest group of women.

\section{General Discussion}

Overall, results across these two studies confirm that individual differences in heteronormativity are associated with ally activism among straight women and in a small sample of contemporary straight male college students. The only group for whom this relationship did not hold was the oldest cohort of straight women alumnae, those already in their 60s in 1996. Thus, the results were mostly consistent despite substantial age differences, and the use of very different indicators of heteronormativity. This consistency underscores the value of assessing the degree to which straight individuals endorse or reject heteronorms in studying their motivation to engage in ally activism on behalf of sexual minorities. The 
consistency may also reflect findings culturally bound to the United States; it remains an empirical question how heteronormativity and ties between gay and straight individuals operate in other cultures.

Both measures of heteronormativity have clear limitations. They depend on explicit report of attitudes, feelings, and expectations, though considerable research has shown that implicit endorsement of norms may yield different results from such explicit measures (Hegarty \& Pratto, 2004). We are currently exploring whether a measure of implicit resistance to heteronormativity corresponds to higher levels of political participation. Furthermore, awareness of privilege among the college students, was not associated with resistance to heteronormativity, perhaps because scores were uniformly very high on this measure for this sample. Moreover, among the straight men it was not significantly associated with lesbian/gay rights activism. These results raise questions for us about how best to assess people's awareness of privilege. Although our items do provide an indicator of awareness of personal privilege, they do not assess whether the individual feels this privilege is unearned or unjust. Future studies should attempt to develop a scale with more variance in college-educated samples, and should distinguish the judgment of the legitimacy of privilege (like the item assessing discontent with the power lesbians have in Study 2) from mere acknowledgement of one's own privilege.

The value of intersectionality as a conceptual tool in thinking about privilege is clear. Because of the specific intersection of gender and sexuality that they experience, we anticipated that straight women would score lower in heteronormativity and higher in awareness of heterosexual privilege, as indeed they did. Moreover, both of those scores were associated with lesbian/gay rights activism for straight women. Because we have much more data from women than men in these two studies, it is important for future research to focus particularly on the conditions under which straight men develop a critical perspective on their privilege that motivates activism (Coston \& Kimmel, 2012).

\section{References}

Berube, A. (2003). How gay stays White and what kind of White it stays. In M. S. Kimmel \& A. L. Ferber (Eds.), Privilege: A reader (pp. 253-283). Boulder, CO: Westview Press.

Brewer, P. R. (2003). The shifting foundations of public opinion about gay rights. Journal of Politics, 65, 1208-1220. doi:10.1111/1468-2508.t01-1-00133.

Brewer, P. R., \& Wilcox, C. (2005). The polls-trends: Same-sex marriage and civil unions. Public Opinion Quarterly, 69, 599-616. doi:10.1093/poq/nfi052.

Burns, A. (2004). The racing of capability and culpability in desegregated schools: Discourses of merit and responsibility. In M. Fine, L. Weis, L. P. Pruitt, \& A. Burns (Eds.), Off white: Readings on power, privilege, and resistance (2nd ed., pp. 373-394). New York: Routledge.

Case, K. A. (2012). Discovering the privilege of whiteness: White women's reflections of anti- racist identity and ally behavior. Journal of Social Issues, 68, 78-96. 
Cole, E. R. (2008). Coalitions as a model for intersectionality: From practice to theory. Sex Roles, 59, 443-453. doi:10.1007/s11199-008-9419-1.

Cole, E. R. (2009). Intersectionality and research in psychology. American Psychologist, 64(3), 170180. doi:10.1037/a0014564.

Cole, E. R., Avery, L., Dodson, C., \& Goodman, K. D. (2012). Against nature: How essentialist discourses in the debates on marriage law privilege heterosexuality and whiteness. Journal of Social Issues, 68, 46-62.

Cole, E. R., \& Luna, Z. (2010). Making coalitions work: Solidarity across differences within U.S. feminism. Feminist Studies, 36(1), 71-98.

Coston, B. M., \& Kimmel, M. (2012). Seeing privilege where it isn't: Marginalized masculinities and the intersectionality of privilege. Journal of Social Issues, 68, 97-111.

Dalley, P., \& Campbell, M. (2006). Constructing and contesting discourses of heteronormativity: An ethnographic study of youth in a Francophone high school in Canada. Journal of Language, Identity, and Education, 5(1), 11-29.

Duncan, L. E. (1999). Motivation for collective action: Group consciousness as mediator of personality, life experiences, and women's rights activism. Political Psychology, 20, 611-635. doi:10.1111/0162-895X.00159.

Eagly, A. H. (1987). Sex differences in social behavior: A social-role interpretation. Hillsdale, NJ: Erlbaum.

Egan, P. J., Persily, N., \& Wallsten, K. (2008). Gay rights. In N. Persily, J. Citrin, \& P. J. Egan (Eds.), Public opinion and constitutional controversy (pp. 234-266). New York: Oxford University Press.

Egan, P. J., \& Sherrill, K. (2005). Neither an in-law or an out-law be: Trends in America's attitudes towards gay people. Public Opinion Pros: An Online Magazine for the Polling Professional (and Everyone Else). (Downloaded November 11, 2010 from http://www. publicopinionpros.norc.org/).

Goffman, E. (1963). Stigma and sexual orientation: Understanding prejudice against lesbians, gay men and bisexuals. Newbury Park, CA: Sage.

Gurin, P., Miller, A., \& Gurin, G. (1980). Stratum identification and consciousness. Social Psychology Quarterly, 43, 30-47. doi:10.2307/3033746.

Habarth, J. (2008). Thinking 'straight': Heteronormativity and associated outcomes across sexual orientation. Doctoral Dissertation. University of Michigan, Ann Arbor, MI.

Hegarty, P., \& Pratto, F. (2004). The differences that norms make: Empiricism, social constructionism and the interpretation of group differences. Sex Roles, 50, 445-453. doi:10.1023/B:SERS.0000023065.56633.cb.

Hegarty, P., Pratto, F., \& Lemieux, A. (2004). Heterosexist ambivalence and heterocentric norms: Drinking in intergroup discomfort. Group Processes \& Intergroup Relations, 7(2), 119-130. doi: $10.1177 / 1368430204041399$.

Herek, G. (1988). Heterosexuals' attitudes toward lesbians and gay men: Correlates and gender differences. Journal of Sex Research, 25(4), 451-477. doi:10.1080/00224498809551476.

Hequembourg, A., \& Brallier, S. (2009). An exploration of sexual minority stress across the lines of gender and sexual identity. Journal of Homosexuality, 56(3), 273-298. doi:10.1080/00918360902728517.

Hill Collins, P. (2003). Toward a new vision: Race, class, and gender as categories of analysis and connection. In M. S. Kimmel \& A. L. Ferber (Eds.), Privilege: A reader (pp. 331-348). Boulder, CO: Westview Press.

Huddy, L., Neely, F. K., \& Lafay, M. R. (2000). The polls-trends: Support for the women's movement. Public Opinion Quarterly, 64, 309-350. doi:10.1086/317991.

Hunter, D. (2010). Daily effects of straight privilege. (Downloaded January 30, 2010 from http://www.cs.earlham.edu/ hyrax/personal/files/student_res/straightprivilege.htm).

Hurtado, A. (1996). The color of privilege: Three blasphemies on race and feminism. Ann Arbor: University of Michigan Press.

Ingraham, C. (1996). The heterosexual imaginary. In S. Seidman (Ed.), Queer theory/sociology (pp. 168-193). Oxford: Blackwell. 
Ingraham, C. (1999). White weddings: Romancing heterosexuality in popular culture. New York: Routledge.

Iyer, A., Leach, C. W., \& Pedersen, A. (2004). Racial wrongs and restitutions: The role of guilt and other group-based emotions. In M. Fine, L. Weis, L. P. Pruitt, \& A. Burns (Eds.), Off White: Readings on power, privilege, and resistance (2nd ed., pp. 345-361). New York:Routledge.

Kitzinger, C. (2005). Heteronormativity in action: Reproducing the heterosexual nuclear family in after-hours medical calls. Social Problems, 52(4), 477-498. doi:10.1525/sp.2005.52.4.477.

Mann, B. (2007). The lesbian June Cleaver: Heterosexism and lesbian mothering. Hypatia, 22, $149-$ 167. doi:10.2979/HYP.2007.22.1.149.

Massey, S. G. (2009). Polymorphous prejudice: Liberating the measurement of heterosexuals' attitudes toward lesbians and gay men. Journal of Homosexuality, 56(2), 147-172. doi:10.1080/00918360802623131.

Messner, M. A. (2003). Becoming 100 percent straight. In M. S. Kimmel \& A. L. Ferber (Eds.), Privilege: A reader (pp. 181-188). Boulder, CO: Westview Press.

McIntosh, P. (1988). White privilege and male privilege: A personal account of coming to see correspondences through work in women's studies. Working Paper No. 189. Wellesley, MA: Wellesley Centers for Women.

Miller, W. E. (1982). American national election study, 1980. Ann Arbor, MI: Inter-University Consortium for Political and Social Research.

Nielson, J. M., Walden, G., \& Kunkel, C. A. (2000). Gendered heteronormativity: Empirical illustrations in everyday life. The Sociological Quarterly, 41(2), 283-296. (Downloaded January 15, 2010 from http://www.jstor.org/).

Pratto, F., \& Stewart, A. L. (2012). Group dominance and the half-blindness of privilege. Journal of Social Issues, 68, 28-45.

Rosenfeld, D. (2009). Heteronormativity and homonormativity as practical and moral resources: The case of lesbian and gay elders. Gender \& Society, 23(5), 617-638. doi: $10.1177 / 0891243209341357$.

Russell, G. M. (2011). Motives of heterosexual allies in collective action for equality. Journal of Social Issues, 67(2), 376-393. doi:10.1111/j.1540-4560.2011.01703.x.

Stewart, A., \& Healy, J. M. (1989). Linking individual development and social changes. American Psychologist, 44, 30-42. doi:10.1037//0003-066X.44.1.30.

Stewart, A. J., \& McDermott, C. (2004). Gender in psychology. Annual Review of Psychology, 55, 519-544. doi:10.1146/annurev.psych.55.090902.141537.

Stewart, T. L., Latu, I. M, Branscombe, N. R., Philips, N. L., \& Denney, H. T. (2012). Reducing prejudice through seeing and believing: The additive effects of white privilege awareness and perceived efficacy to enact change. Journal of Social Issues, 68, 11-27.

Wilkinson, S., \& Kitzinger, C. (Eds.). (1993). Heterosexuality: A feminism and psychology reader. London: Sage.

Zucker, A. N. (1998). Understanding feminist identity in three generations of college-educated women. Doctoral Dissertation. University of Michigan, Ann Arbor, MI.

SAMANTHA A. MONTGOMERY is a PhD candidate in the joint Women's Studies and Personality and Social Contexts Psychology program at the University of Michigan. Her research examines individual differences in the adherence to prescriptive gender roles and normative expectations about heterosexuality. Specifically, she is interested in heteronormativity and how it relates to important life outcomes and political engagement.

ABIGAIL J. STEWART is Sandra Schwartz Tangri Professor of Psychology and Women's Studies at the University of Michigan and director of the UM 
ADVANCE project. She holds degrees from Wesleyan University (BA), London School of Economics (MSc), and Harvard University (PhD). She has received the Henry Murray Award (in personality psychology) and the Carolyn Wood Sherif Award (in psychology of women) from the American Psychological Association. Dr. Stewart has published many scholarly articles and several books, focusing on the psychology of women's lives, personality, and adaptation to personal and social changes. Her current research, which combines qualitative and quantitative methods, includes comparative analyses of longitudinal studies of educated women's lives and personalities, research on gender, race and heteronormativity, and research and interventions on gender and science and technology with students and faculty. 